\title{
Effects of Steroidal and Non Steroidal Drugs on the Neovascularization Response Induced by Tumoral TA3 Supernatant on CAM from Chick Embryo
}

\author{
JORGE ZÚÑIGA ${ }^{1}$, MARCELA FUENZALIDA ${ }^{1}$, ANÍBAL GUERRERO ${ }^{1}$, \\ JULIO ILLANES, ALFREDO DABANCENS ${ }^{2}$, EUGENIA DÍAZ ${ }^{1}$ and DAVID LEMUS ${ }^{1}$
}

${ }^{1}$ Laboratory of Experimental Embryology, Program of Morphology (ICBM), Faculty of Medicine, University of Chile.

${ }^{2}$ Pathological Anatomy Institute, Clinical Hospital JJ Aguirre, University of Chile

\begin{abstract}
Angiogenesis, the development of new blood vessels from the existing vascular network, may result as a consequence of the increase or decrease of proangiogenic or antiangiogenic factors, respectively. The tumor itself could up-regulate the production of angiogenic factors. Recently, we established that the steroidal drug betamethasone in low concentration inhibit the neovascularization promoted by TA3 Ts on CAM of chick embryos. We describe here the effects of the non-steroidal drug ketoprofen, alone or in association with betamethasone, on the angiogenesis promoted by TA3 Ts on CAM. The main finding reported here is that the formation of new blood vessels is strongly inhibited by low concentrations of ketoprofen. The association of both drugs produced a synergistic effect, significantly decreasing tumoral supernatant angiogenesis. It is known that steroidal anti-inflammatory drugs inhibit the enzymes required for the production of prostaglandins through a nuclear GR mediated mechanism. This may operate as a general mechanism in endothelial cells as well. Considering that the induction of COX 1 and COX2 are inhibited by ketoprofen, and that these enzymes are located in the stromal compartment of the CAM, we propose that its antiangiogenic effect may occur via inhibition of the two COX isoforms. In fact, we found that ketoprofen induced apoptosis in both the stromal fibroblast and endotelial cells. The potentiated effect of the combination of betamethasone and ketoprofen may have some therapeutic projections in the control of pathological angiogenesis.
\end{abstract}

Key terms: Angiogenesis, Antiangiogenesis, Tumor, betamethasone, ketoprofen.

\section{INTRODUCTION}

Angiogenesis is the development of new blood vessels and capillaries from the existing vascular bed. Under normal conditions, this tightly regulated process occurs only during embryonic development, in the female reproductive cycle, and during wound repair. However, in pathological conditions such as malignant growth, atherosclerosis, and diabetic retinopathy, angiogenesis becomes persistent. It has been demonstrated that this prevalence is mainly due to an imbalance in the interplay between positive and negative endothelial regulatory signals that control this process (Toi et al., 2001).
It is well known that angiogenesis promotes both the spread and metastasis of tumors. In fact, an increasing amount of experimental evidence indicates that tumor growth and lethality are both dependent on angiogenesis. It has been proposed that in order to stimulate angiogenesis, the tumor up-regulates the production of a variety of angiogenic factors such as a-FGF and bFGF, as well as VEGF/VPF (Kandel et al., 1991). Recently however, specific inhibitors of angiogenesis generated by malignant tumors, namely endostatin (O'Reilly et al., 1997) and thrombospondin (Good et al., 1990; Frank et al., 2002), have been described. Other endogenous inhibitors of 
angiogenesis have also been identified, although not all of them are associated with tumor presence. These include platelet factor 4 (Grupta et al. 1995), interferonalpha and interferon-inducible protein 10 (Strieter et al., 1995; Angiolillo et al., 1995). All of these agents are induced by interleukin-12 and/or interferon-gamma (Voest et al., 1995), gro-beta (Cao et al., 1995), and the $16 \mathrm{kDa}$ N-terminal fragment of prolactin (Clapp et al., 1993). It has been clearly established that when tumoral angiogenesis is suppressed by the administration of agents that specifically inhibit the growth of vascular endothelial cells, the tumor remains dormant, limited in size, and essentially harmless (Malonne et al., 1999; Folkman J. 2000). The MCD and its correlation with other anatomical and clinical parameters such as VEGF expression, tumoral oxygenation, nutrient supply and tissue $\mathrm{pH}$, could be used as reliable markers of prognosis (Pilch et al., 2000). On the other hand, normal organogenesis and development are controlled by the balance between cell proliferation and apoptosis, and there is strong evidence that tumor growth is not only the result of uncontrolled proliferation, but also of reduced apoptosis (Reed 1999). The balance between proliferation and apoptosis is crucial in determining the overall growth or regression of the tumor (Tamm et al., 2001). A number of studies in both rodent cancer models and human cancer have shown that NSAIDs have anti-neoplastic properties (Williams et al., 2000).

We recently established that a low concentration of betamethasone $(0.08 \mu \mathrm{g} /$ $\mathrm{ml}$ ) produced a considerable inhibition of the neovascularization promoted by TA3 Ts from AJ strain mice on the CAM of 12-day chick embryos. This was established as the minimal antiangiogenic concentration $(\beta$ MAAC) (Lemus et al., 2001).

In the present work, we describe the effects of the steroidal anti-inflammatory agent betamethasone and the NSAID ketoprofen, administered either alone (MAAC) or associated (half MAAC each), on CAM angiogenesis promoted by the tumor supernatant $\left(\mathrm{TA}_{3}\right.$ ts).

\section{METHODS}

The host chick CAM assay was prepared as follows: White Leghorn fertilized eggs were kept in an incubator at $38.2{ }^{\circ} \mathrm{C}$ in a humidified atmosphere. At stage 20 (Hamburger and Hamilton, 1951) a square window was opened in the eggshell and 2 $\mathrm{ml}$ of albumen were removed so that the developing CAM became detached from the shell, exposing the underlying blood vessels. The window was then sealed using clear adhesive tape and the host eggs were incubated undisturbed until the day of the experiment. CAM primitive blood vessels proliferated and differentiated into an arterial and venous system until day 8 . Thus, a network of capillaries originated and migrated to occupy a particular area beneath the chorion and mediate gas exchanges with the outer environment. A rapid endothelial cell proliferation followed until day 12; thereafter, their mitotic index declined just as rapidly and the vascular system attained its final arrangement on day 18 , just before hatching. The number of blood vessels in normal conditions was evaluated as the total number of capillaries visualized in an area equivalent to 0.080 $\mathrm{mm}^{2}$ from an eye-piece reticule, on normal 12-day old chicken embryo CAM.

Regarding the experimental conditions, on developmental day 8 , previously sterilized methylcellulose discs $(5 \mathrm{~mm}$ in diameter, $0.25 \mathrm{~mm}$ pore size, $125 \mathrm{~mm}$ thick) were instilled with $10 \mathrm{ml}$ of PBS. They were placed on the surface of the growing CAM, in direct contact with a well-vascularized region in order to asses the level of inflammatory angiogenesis in response to the implant alone. A summary of the experimental conditions is depicted in Figure 1. In all cases, the CAM response was determined 48 hours after implantation, on developmental day 10 . To study the effects of steroidal and NSAIDs on angiogenesis, betamethasone and ketoprofen were tested either alone or associated. For this purpose, on developmental day 10 , the implanted discs were instilled with $10 \mathrm{ul}$ of each drug. The effective ketoprofen MAAC, i.e. the concentration of drug required to obtain a 
2 Days of Incubation

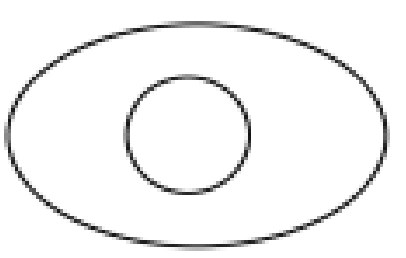

Control No Disc

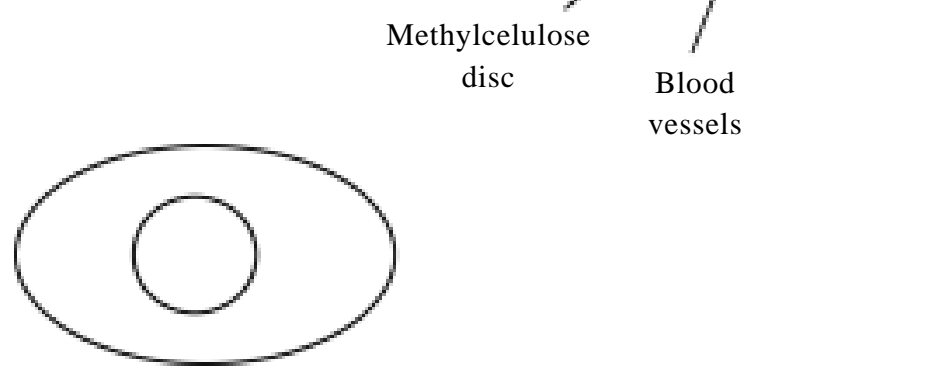

8 Days
Implanted discs

$\frac{10 \text { Days }}{\text { Instillation }}$
12 Days

Quantificaton of vascular density

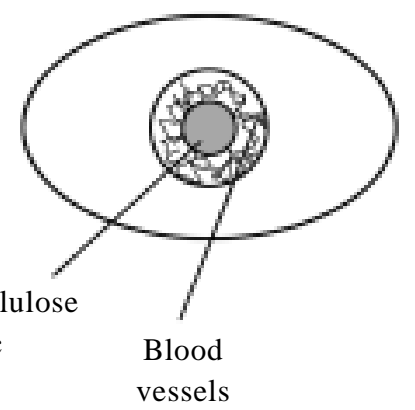

PBS

Betamethasone

Ketoprofen

Betam + Ketop

Ts

Betamethasone + Ts

Ketoprofen + Ts

Betam + Ketop + Ts

\section{Figure 1}

Diagram showing the experimental design. At 2 days of incubation, a window was opened into the eggshell. At 8 days, sterile methylcellulose discs were placed in contact with CAM blood vessels. On day 10, new discs instilled with the appropriated substances were placed onto the CAM. After 48 hours of further incubation (12 days), these discs were removed, the CAM was excised and fixed and the vascular density was assessed. Ts: tumoral supernatant.

MCD similar to that observed in the control, was previously determined by the implantation of disc instilled in decreasing concentrations of the drug. Ketoprofen MAAC resulted to be $200 \mu \mathrm{g} / \mathrm{ml}$. A summary of the drug concentrations used in the different treatments is presented in Table I.
TA3 tumor was provided by the Pathology Program of the Biomedical Sciences Institute. This is an ascitic mammary gland carcinoma maintained by means of consecutive transference into the peritoneal cavity of AJ strain mice, performed every 7 days (Zipper et al., 1995). In order to obtain the tumoral

TABLE I

Drug concentration in each experimental condition

Condition $(*)$

Drug

Concentration $(\mu \mathrm{g} / \mathrm{ml})$

Betamethasone

Ketoprofen

$50 \%$ Betamethasone $+50 \%$ Ketoprofen

Tumoral supernatant (TA3 Ts)

PBS (Control)

0.08
200
$0.04+100$

-

$-$

(*) Volumes corresponded to $10 \mu \mathrm{l}$ in each experimental condition 
supernatant, mice were anesthetized with ether and sacrificed. Then, the ascitic tumor was extracted by aspiration $(1 \mathrm{ml})$, and centrifuged at $1,085 \mathrm{~g}$ for $3 \mathrm{~min}$. The tumor supernatant was then separated from the cells. A volume of $10 \mu \mathrm{l}$ of the TA3 Ts was instilled onto the methylcellulose discs, according to a previously described procedure (Illanes et al., 1999).

After disc implantation, host eggs were further incubated for 48 hours. At the end of the culture period (at day 12 of embryonic development) the implants were surgically removed, photographed, and fixed in $10 \%$ formaldehyde. The tissues were processed using an auto-technicon apparatus through increasing concentrations of ethanol and infiltrated in paraffin (melting point $58-60^{\circ} \mathrm{C}$ ). In order to determined the main zone of angiogenesis in the CAM, histological sections of $5 \mu \mathrm{m}$ thick were obtained, from which three were processed in parallel. Sections one and three were stained with hematoxylin-eosin, while section number two was processed using the TUNEL assay (Gavrieli et al., 1992). Five independent observers analyzed the CAM response. Comparisons of blood vessels density between the control and the different experimental conditions were performed using ANOVA test. A total of 135 fertilized eggs, 15 in each treatment, were employed in this study.

\section{RESULTS}

An intense and significant neo-angiogenesis was observed on the surface of the growing CAM two days after the implantation of methylcellulose discs impregnated in either PBS (8.78 \pm 0.20 capillaries per area) or Ts $(10.15 \pm 0.12$ capillaries per area). In both cases, the MCD increased significantly when compared to the control value (MCD $=7.01 \pm 0.17$ capillaries per area, counted on normal CAM of 12-day chick embryo). Figure 2 clearly shows that the increase in neoangiogenesis was even more pronounced when the disc was impregnated with Ts (tumoral angiogenesis) than PBS (inflammatory angiogenesis; $\mathrm{p}<0.001$ in both cases).

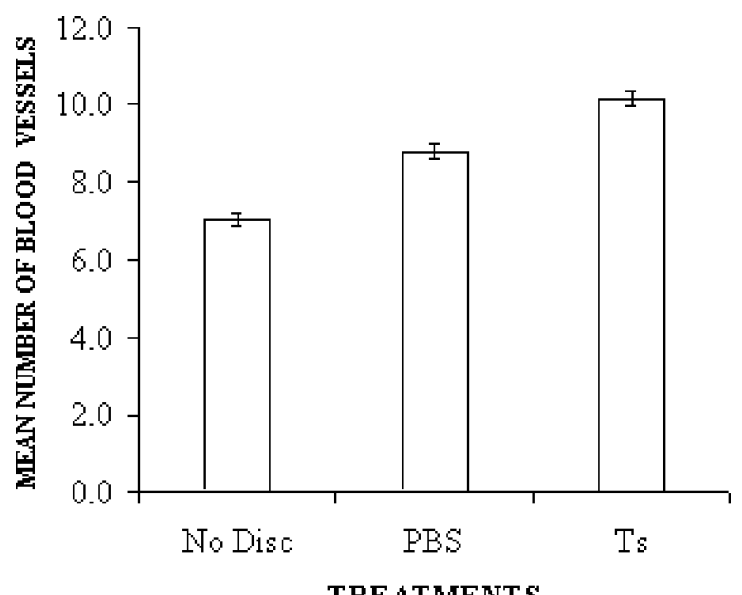

TREATMENTS

\section{Figure 2}

Normal (No Disc), inflammatory (PBS) and tumoral supernatant (Ts) angiogenesis in 12-day old chick embryo CAM. Millipore discs instilled either with PBS or Ts induced a significant amount of neo-angiogenesis when implanted on chick embryo CAM at developmental day 10 . Note that tumoral angiogenesis is more pronounced than the inflammatory response. Capillary density was determined in a $2250 \mu \mathrm{m}^{2}$ area. ANOVA test and Bonferroni correction for multiple comparisons, $\mathrm{p}<0.01$.

Regarding the effects of steroidal (betamethasone) and NSAID (ketoprofen), we observed that CAMs treated with the MAAC of these agents displayed a highly significant decrease in the MCD $(2.48 \pm 0.21$ and $3.66 \pm 0.15$ capillaries per area for betamethasone and ketoprofen, respectively) compared with the PBS impregnated control $(8.78 \pm 0.20)$. However, when the association of both agents (half MAAC of each) was analyzed, an even more drastic decrease in the MCD was seen $(0.99 \pm 0.01)$. All the comparisons were highly significant $(\mathrm{p}<0.001$, see Fig. 3).

With respect to the effects of these drugs on tumoral angiogenesis, CAMs treated with TA3 Ts in combination with betamethasone or with ketoprofen, or a combined treatment with both agents applied together, a clear anti-angiogenesis response was induced. This is depicted in Figure 4, which shows that betamethasone+Ts and ketoprofen+Ts reduced the proliferation of capillaries to $2.62 \pm 0.05$ and $1.94 \pm 0.06$ respectively, 
compared to the mean value obtained for CAMs treated with Ts $(10.15 \pm 0.19)$. It must be pointed out that the antiangiogenic effect of ketoprofen was more pronounced on tumoral angiogenesis than that observed in inflammatory angiogenesis (compare Fig. 3 and Fig. 4).

Light microscopy observation of histological sections from CAMs instilled with ketoprofen and the association of ketoprofen and betamethasone revealed the presence of some endothelial as well as stromal cells showing apoptosis (see Fig. 5). This phenomenon, however, was not detected in CAMs treated with betamethasone.

\section{DISCUSSION}

The process of angiogenesis is the result of the increase of proangiogenic agents or the decrease of antiangiogenic factors. The antiangiogenic effect of some corticosteroids in combination with heparine has been well established (Folkman 1989). A direct antiangiogenic effect of betamethasone has recently been reported (Lemus et al., 2001) and it is confirmed in the present study.

The main finding of the present work is that the formation of new blood vessels, induced by methylcellulose discs impregnated with PBS and Ts, was inhibited in the presence of low concentrations of betamethasone and/or ketoprofen. However, the mechanisms through which these antiinflammatory drugs could regulate the growth of endothelial cells on MAC are still not fully understood. A modular hypothesis has been proposed in order to explain the effects of glucocorticoid drugs. Briefly, genomic effects occur at very low doses. Significant increases in the dose of steroidal drugs may bring about additional therapeutic benefits, mediated by membrane-bound receptors and/or physicochemical interactions with the cell membrane (Buttgereit et al., 1998). The fact that the concentration of betamethasone needed in the present study to obtain a minimum antiangiogenic effect was in the range of $2 \times 10^{-7}$ moles/litre (Lemus et al., 2001), seems to indicate that its effect may most likely be genomically mediated.

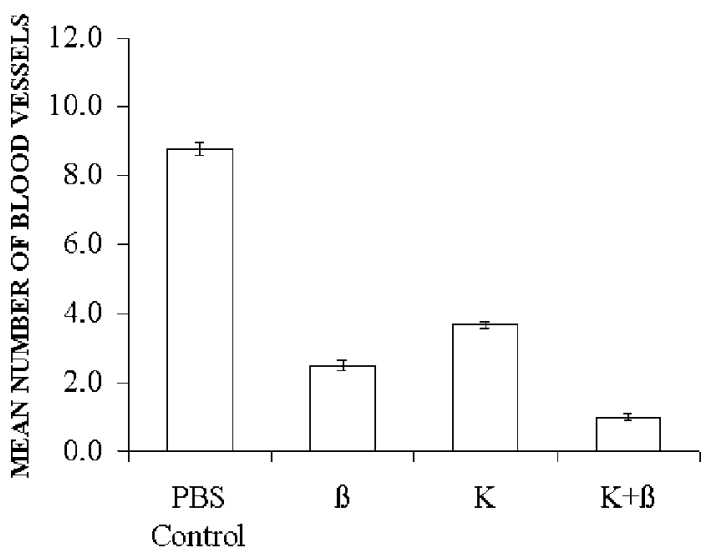

TREATMENTS

Figure 3

Effects of Betamethasone ( $($ ), ketoprofen (K) and its combination $(\beta+K)$ on the inflammatory angiogenesis. These drugs have a potent antiangiogenic effect, manifested as a significant decrease in the number of blood vessels observed in 12-day old chick embryo CAM. Treatment with half the dose of both agents, applied simultaneously $(B+K)$, strengthened this effect and induced an even more drastic angiogenesis decrease. Capillary density was determined in a $2250 \mu \mathrm{m}^{2}$ area. ANOVA test and Bonferroni correction for multiple comparisons, $\mathrm{p}<0.01$.

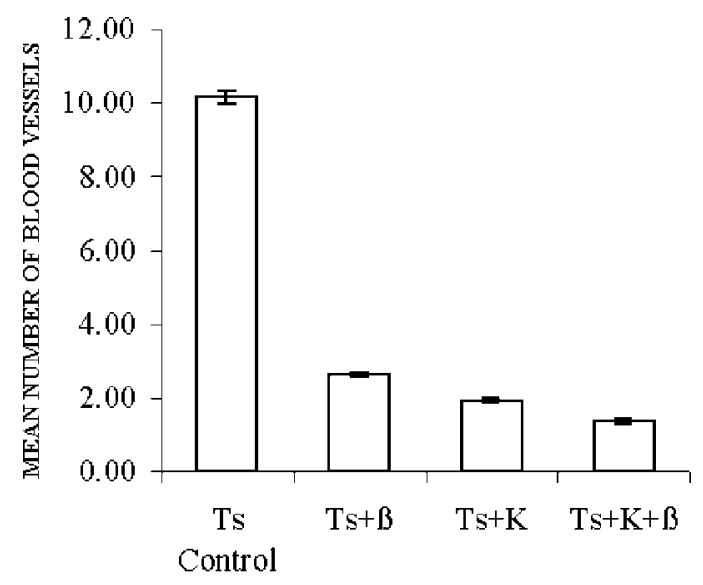

TREATMENTS

\section{Figure 4}

Effects of Betamethasone (Ts+ß), ketoprofen $(\mathrm{T} s+\mathrm{K})$ and its combination $(\mathrm{Ts}+\beta+\mathrm{K})$ on tumoral angiogenesis. Both drugs induced a significant reduction of the tumoral angiogenesis in 12-day old chick embryo CAM. Note that the combination of both drugs, in half MAAC, significantly strengthened this decrease. ANOVA test and Bonferroni correction for multiple comparisons, $\mathrm{p}<0.01$. 


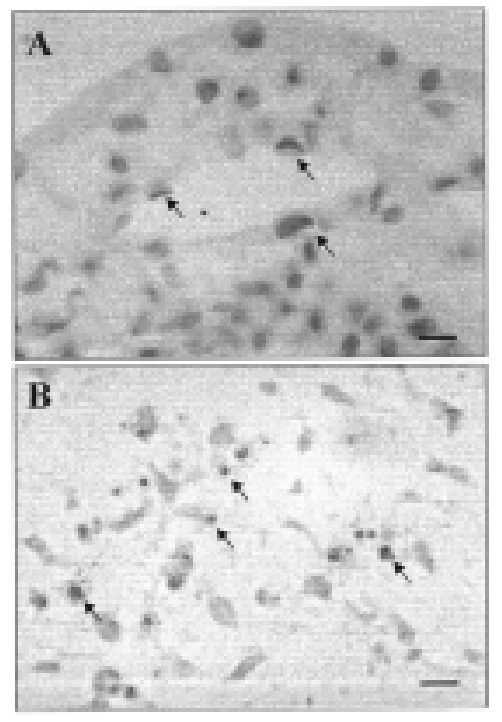

Figure 5. Light microscopy photograph showing apoptotic endothelial and stromal cells in 12-day old chick embryo CAM treated with ketoprofen for $48 \mathrm{hrs}$. Histological sections were processed using the TUNEL detection method. A) Endothelial cells showing apoptotic nuclei characterized by DNA condensation (arrows). B) Stromal region of the CAM showing TUNEL positive cells with apoptotic bodies (arrows). Magnification bar: $A=10 \mathrm{~mm}, \mathrm{~B}=20 \mathrm{~mm}$.

The nuclear receptor-dependent action of glucocorticoids, on the contrary, has been fairly well investigated (Boumpas et al., 1993; Barnes and Adcock, 1993). In general, the classic receptor-mediated action of glucocorticoids results in the increase in the transcriptional rate of certain genes. Translation then leads to an increased production of the targeted proteins. Among the more important are the proteins of the annexin family, endonucleases, neutral endopeptidases and angiotensin-converting enzyme. Of greatest importance for the anti-inflammatory action of glucocorticoids is lipocortin 1, which inhibits phospholipase $\mathrm{A}_{2}$ on the arachidonic acid cascade which in turn inhibits the synthesis of mediators of inflammation (Goulding and Guyre, 1993). In this way, glucocorticoids also inhibit the synthesis of various cytokines, such as tumor necrosis factor $\alpha$, IL-2 and IL-6 (Buttgereit et al., 1995). The induction of nitrogen monoxide synthase and inducible COX-2 are also inhibited by glucocorticoids. The protein-protein interaction between activated $\mathrm{GR} \alpha$ and the transcriptions factors activator protein 1 and nuclear factor $\kappa \beta(\mathrm{NF}-\kappa \beta)$ plays an important role in the inhibition of COX-2 (Boumpas, 1996). In addition, it has also been reported that oncogene-induced transcription in response to growth factor stimulation can be effectively inhibited, or totally obliterated by addition of corticoids. The decisive element is the AP-1 binding site which interfere with the nuclear GR. In this way, corticoids stimulate cell differentiation, bringing them out of the cell cycle. It is known that in cells deficient in GR, corticoids do not inhibit the proliferative cycle. This has been demonstrated in cells of mesenchymal origin such as fibroblasts and adipocytes (Radler-Pohl et al., 1993).

We postulate that the interference with nuclear GR could also operate as a general biological mechanism in endothelial cells. Furthermore, in relation to the effects of glucocorticoids in transcription, there are also post-transcriptional effects that primarily affect mRNA stability, translation, and secretion (Ristimäki et al., 1996; Fessler et al., 1996). For example, it has been shown that glucocorticoids play an important role in the destabilization of the COX-2 transcripts during the IL-1-induced expression of COX-2 mRNA (Buttgereit et al., 1998). Consequently, posttranscriptional mRNA destabilization may be an important mechanism in the antiinflammatory action of glucocorticoids. Furthermore, using in vitro assays it has been demonstrated that COX-2 can influence angiogenesis (Daniel et al., 1999) and that treatment with a selective COX-2 inhibitor, effectively prevents this angiogenesis (Yamada et al., 1999). COX catalyzes the first step of the arachidonic acid metabolism in the synthesis of prostaglandins. From the two known isoforms, COX-1 is expressed in most tissues and it is responsible for the physiological production of prostaglandins. COX-2 expression, on the other hand, is induced in the inflammatory tissue and it is 
responsible for the production of prostaglandins during inflammation. One known property of the NSAIDs is their ability to inhibit COX-1 and COX-2 (Williams et al., 2000). Therefore, we speculate that the antiangiogenic effect of ketoprofen may occur via inhibition both isoforms of $\mathrm{COX}$. Considering that $\mathrm{COX}-1$ and COX-2 may be located in the stromal compartment of the CAM, ketoprofen may lead to an inhibition in the production of proangiogenic factors, as is observed in the inflammatory and tumoral angiogenesis analyzed in the present work. In this regard, it has been shown that the expression of VEGF by host fibroblast plays an important role in angiogenesis (Fukumura et al., 1998) and that prostaglandins can regulate VEGF and bFGF expression (Hoper et al., 1997, Cheng et al., 1997). In addition, COX inhibitors can directly affect angiogenesis (Daniel et al., 1999, Yamada et al., 1999). With regard to the effect of the combination of betamethasone and ketoprofen assessed in the present work, it is possible that these drugs may be acting synergistically as antineoangiogenic factors on CAM.

If we consider that CAM angiogenesis induced by TA3 Ts is a response to both the cellular microenvironment as well as some molecular signals that participate in tumor-host cross-talk, then the most promising cellular target for antiangiogenesis may be the stromal fibroblasts and the endothelial cells. The results showed here indicate that betamethasone did not induce apoptosis, suggesting that the concentration utilized ( 0.08 $\mu \mathrm{g} / \mathrm{ml}$ ) may be considered a subapoptotic dose. Ketoprofen, on the other hand, induced apoptosis in both cell types. The specific mechanisms underlying this phenomenon are not clear, although two major mechanisms, mitochondrial and death receptor pathway, both involving caspase activation, have been described (Parton, et al., 2001). It is reasonable to assume that ketoprofen may be acting through one of these.

In summary, the association of betamethasone and ketoprofen effectively decreased both the inflammatory and the tumoral supernatant angiogenesis. This effect may occur by the synergistic action of both drugs. This potentiation may allow the use of even lower concentration of these agents, which in turn, may have therapeutic projections in the control of pathological angiogenesis, such as in ischaemic and inflammatory diseases and cancer. Further studies are necessary to validate these propositions.

\section{ACKNOWLEDGEMENTS}

This research was supported by Fondo Nacional de Investigación Científica y Tecnológica (FONDECYT) Grant 1990852 to D.L. The authors thank the anonymous reviewers for their valuable comments on the manuscript.

This paper is a portion of the Master of Medical Science thesis of Jorge Zúñiga.

\section{REFERENCES}

ANGIOLILLO A, SGADARI C, TAUB D, LIAO F, FARBER J, MIAHESHWARI S (1995) Human interferon-inducible protein (IP-10), a member of the c$\mathrm{x}-\mathrm{c}$ chemokine family, is an inhibitor of angiogenesis. Biochem Biophys Res Comm 210: 51-57

BARNES P, ADCOCK I (1993) Anti-inflammatory actions of steroids: molecular and mechanisms. Trends Pharmacol Sci 14: 436-41

BOUMPAS D, CHROUSOS G, WILDER R, CUPPS T, BALOW J (1993) Glucorticoid therapy for immunemediated diseases: basic and clinical correlates. Ann Intern Med 119: 1198-1208

BOUMPAS D (1996) A novel action of glucocorticoids NF- $\kappa \beta$ inhibition. Br J Rheumatol 35: 709-710

BUTTGEREIT F, BRINK I, THIELE B, HIEPE $F$, BURMESTER GR, HALL E (1995) Effects of methylprednisolone and 21-aminosteroids on mitogeninduced IL-6 and TNF-a production in human peripheral blood mononuclear cells. J Pharmacol Exp Ther 275: 850-853

BUTTGEREIT F, WEHLING M, BURMESTER GR (1998) A new hypotesis of modular glucocorticoid actions. Arthritis \& Rheumatism 41: 761-767

CAO Y, CHEN C, WEATHERBEE J, TSANG M, FOLKMAN $\mathrm{J}$ (1995) Gro-beta, a c-X-c chemokine, is an angiogenesis inhibitor that suppresses the growth of Lewis lung carcinoma in mice. J Exp Med 182: 2069-2077

CLAPP C, MARTIAL J, GUZMÁN R, RENTIER-DETRUE F, WEINER R (1993) The 16-kilodalton N-terminal fragment of human prolactin is a potent inhibitor of angiogenesis. Endocrinology 133: 1292-1299

CHENG T, CAO W, WEN R, STEINBERG R, LAVAIL M (1997) Prostaglandin $E_{2}$ induces vascular endothelial growth factor and basic fibroblast growth factor mRNA expression in cultured rat Muller cells. Invest Ophthalmol Vis 39: 581-591

DANIEL T, LIU H, MORROW J, CREWS B, MARNETT L (1999) Thromboxane A2 is a mediator of 
cyclooxygenase-2-dependent endothelial migration and angiogenesis. Cancer Res 59: 4574-4577

FESSLER B, PALIOGIANI F, HAMA N, BALOW J, BOUMPAS D (1996) Glucocorticoids modulate CD28 mediated pathways for interleukin 2 production in human $\mathrm{T}$ cells: evidence for postranscriptonal regulation. Transplantation 62: 1113-1118

FOLKMAN J (1989) What is the evidence that tumors are angiogenesis dependent? J Natl Cancer Inst: 82: 4-6

FOLKMAN J (2000) Cancer Medicine IN: HOLLAND JF (ed), Ontario, Canada: Decker. pp: 132-152

FRANK K, REIHER F, VOLPERT O, JIMÉNEZ B, CRAWFORD S, DINNEY C, HENKIN J, HAVIV F, BOUCK N, CAMPBELL S (2002) Inhibition of tumor growth by systemic treatment with thrombospondin-1 peptide mimetics. Inc J Cancer 98:682-689

FUKUMURA D, XAVIER R, SUGIURA T, CHEN Y, PARK EC, LU N (1998) Tumor induction of VEGF promoter activity in stromal cells. Cell 94: 715-725

GAVRIELI Y, SHERMAN Y, BEN-SASSON S (1992) Identification of programmed cell death in situ via specific labeling of nuclear DNA fragmentation. J Cell Biol 119: 493-501

GATELY S, TWARDOWSKI P, STACK MS, PATRICK M, BOGGIO L, CUNDIFF DL (1996) Human prostate carcinoma cells express enzymatic activity that converts human plasminogen to the angiogenesis, angiostatin. Cancer Res 56: 4887-4990

GOOD DJ, POLVERINI PJ, RASTINEJAD F, LE BEAU MM, LEMONS RS, FRAZIER WA (1990) A tumor suppressor-dependent inhibitor of angiogenesis is immunologically and functionally indistinguishable from fragment of thrombospondin. Proc Nat Acad Sci 87: 6624-6628

GOULDING N, GUYRE P (1993) Glucocorticoids, lipocortins and the immune response. Curr Opin Immunol 5: 108-113

GRUPTA S, HASSEL T, SINGH J (1995) A potent inhibitor of endothelial cell proliferation is generated by proteolytic cleavage of the chemokine platelet factor 4. Proc Natl Acad Sci 92: 7799-7803

HAMBURGER V, HAMILTON H (1951) A series of normal stages in the development of the chick embryo. J Morphol 88: 49-92

HOPER M, VOELKEL NF, BATES TO, ALLARD JD, HORAN M, SHEPHERD D (1997) Prostaglandins induce vascular endothelial growth factor in human monocytic cell line and rat lungs via AMP. Am J Respir Cell Mol Biol 17: 748-756

ILLANES J, FUENZALIDA M, ROMERO S, GONZÁLEZ P, LEMUS D (1999) Ethanol effect on the chick embryo ossification: a macroscopic and microscopic study. Biol Res 32: 77-84

KANDEL J, BOSSY-WETZEL E, KLAGSBUM M, FOLKMAN J, HANAHAN D (1991) Neo- vascularization is associated with a switch to the export of bFGF in the multi-step development of fibrosarcoma. Cell 66: 1095-1104

LEMUS D, DABANCENS A, ILLANES J, FUENZALIDA M, GUERRERO A, GONZÁLEZ P (2001) Anti-angiogenic effect of betamethasone on the chick CAM stimulate by TA3 tumor supernatant. Biol Res 34: 227-236

MALONNE H, LANGER I, KISS R, ATASSI G (1999) Mechanisms of tumor angiogenesis and therapeutic implications: angiogenesis inhibitors. Clin Exp Metastasis 17: 1-14

OREILLY MS, BOEHM T, SHING Y, FUKAI N, VASIOS G, LANE WS (1997) Endostatin: An endogenous inhibitor of angiogenesis and tumor growth. Cell 88: 277-285

PARTON M, DOWSETT M, SMITH I (2001) Studies of apoptosis in breast cancer. BMJ 322: 1528-1531

PILCH $\mathrm{H}$, SCHAFFER $\mathrm{U}$, SCHLENGER $\mathrm{K}$, HAWIGHORST $\mathrm{H}$, TANNER B, BAHLMANN $\mathrm{F}$ (2000) L'angiogenese dans le cancer du col uterin. Gynecol Obstet Fertil 28: 29-37

RADLER-POHL S, GEBEL C, SACHSENMAEIR H, KÖNIG M, KRÄMER T, OEHLER M (1993) The activation and activity control of AP-1. Annals New York Acad Sciences 684: 127-148

REED J (1999) Dysregulation of apoptosis in cancer. J Clin Oncol 17: 2941-2953

RISTIMÄKI A, NARKO K, HLA T (1996) Downregulation of cytokine-induced cyclo-oxygenase-2 transcript isoforms by dexamethasone: evidence for post-transcriptional regulation. Biochem J 318:325-331

STRIETER R, KUNKEL S, AREMBERG D, BURDICK M AND POLVERINI P (1995) Human interferoninducible protein 10 (IP-10), a member of the C-X-C chemokine family, is an inhibitor of angiogenesis. Biochem Biophys Res Comm 210: 51-57

TOI M, BANDO H, OGAWA T, MUTA M, HORNIG C, WEICH H (2001) Significance of vascular endothelial growth factor (VEGF)/soluble VEGF receptor-1 relationship in breast cancer. Int J Cancer, Vol 98: 14-18

TAMM I, SCHRIEVER F, DORKEN B (2001) Apoptosis: implications of basic research for clinical oncology. Lancet Oncol 2: 33-42

VOEST E, KENYON B, OREILLY M, TRUITT G, DAMATO R, FOLKMAN J (1995) Inhibition of angiogenesis in vivo by interleukin 12 . J Natl Cancer Ins 87: 581-586

WILLIAMS C, TSUJII M, REESE J, DEY S, DUBOIS R (2000) Host cyclooxygenase-2 modulates carcinoma growth. J Clin Invest 105: 1589-1594

YAMADA M, KAWAI M, KAWAI Y, MASHIMA Y (1999) The effect of selective cyclooxygenase-2-inhibitor on corneal angiogenesis in the rat. Curr Eye Res 19: 300-304

ZIPPER J, DABANCENS A, GUERRERO A, TRUJILLO V (1995) Quinacrine revised. Human Reprod Update 1: 324-342 